\title{
Short Communication: The color fastness of cotton cloth dyed with dye extracted from skin of shallot (Allium ascalonicum)
}

\author{
SARWONO $^{1, \bullet}$, SIGIT SANTOSA ${ }^{2, \bullet \bullet}$, NADIA SIGI PRAMESWARI ${ }^{3}$ \\ ${ }^{1}$ Department of Textile Craft, Faculty of Art and Design, Universitas Sebelas Maret. Jl. Ir. Sutami 36A Surakarta 57126, Central Java, Indonesia. \\ Tel.: +62-271-668682, `email: sarwono59@staff.uns.ac.id \\ ${ }^{2}$ Department of Accountant Education, Faculty of Teacher Training and Education, Universitas Sebelas Maret. Jl. Ir. Sutami 36A Surakarta 57126, \\ Central Java, Indonesia. Tel.: +62-271-669124, vvemail: sigitsantosa@ staff.uns.ac.id \\ ${ }^{3}$ Department of Fine Arts, Faculty of Art and Language. Universitas Negeri Semarang. Jl. Sekaran Raya, Gunung Pati, Semarang 50229, Central Java, \\ Indonesia
}

Manuscript received: 29 June 2019. Revision accepted: 12 August 2019.

\begin{abstract}
Sarwono, Santosa S, Prameswari NS. 2019. Short Communication: The color fastness of cotton cloth dyed with dye extracted from skin of shallot (Allium ascalonicum). Biodiversitas 20: 2475-2479. Inventing new sources of materials in textile coloration industry in Indonesia, especially batik industry, is necessary for the preservation of Indonesia's textile heritage. Focusing on the exploitation of Allium ascalonicum L., this present study aimed at discovering whether shallot skin can be used as a natural dye for textile through the fixation of alum, chalk, and tunjung. It also tried to shed light on the method of applying dye from the skin of shallot to cotton cloth for batik and measured the color fastness. The test of color fastness was done using Staining Scale and Grey Scale. Data were gathered through observation and analyzed descriptively. The results of color fastness test showed that the color fastness of cotton cloth dyed with extract of shallot skin using alum fixation was fairly good based on color change and sufficient based on staining scale. The test results using chalk fixation showed that the color fastness was poor based on color change, but sufficient based on staining scale. Other results with tunjung fixation showed that the color fastness was sufficient.
\end{abstract}

Keywords: Batik, natural dye, shallot skin, textile

\section{INTRODUCTION}

Natural coloring agents can be acquired by extraction of plants easily found in the environment. The sources of natural dyes from plants are wood, bark, twigs, leaves, roots, fruit, seeds or resin and from animal is lac dye (Susanto 1980). The characteristics of natural dyes from plants are influenced by many factors such as species of plants, place of growing, soil fertility, climate, age, time of harvest, and the processing of dyes.

Coloring with natural dyes is preferable because they are environmentally friendly, so the coloring process of textile products can be repeated many times without polluting the environment (Lestari and Prawirohartono 1999). In coloring fabrics using natural dyes, color-locking is done to maintain the color and at the same time to get the color variety obtained from several fixators and different concentrations of the solution so the resulting color display is not monotonous. Natural dyes produce beautiful and distinctive color effects that cannot be imitated by synthetic dyes, so they can improve the attractiveness of the textile products.

Natural dyes can color all textiles made of natural fiber and half synthetic, both cellulose and protein fibers. The examples of cellulose fibers are rayon and cotton, and those of protein fibers are silk and wool. The method of dyeing of a specific medium is influenced by the forms of the raw material (fabric, yarn). Some methods of coloring are brushing, tying, and immersing, depending on the need. There are four basic aspects that must be concerned about in the staining process of the natural dyes, namely mordanting process, extracting process with water solvent, cloth immersion into the solution and improvement of immersion result on the fiber called fixation, and washing.

One source of natural dye for textiles is the skin of shallot or Allium ascalonicum L. (Lestari and Prawirohartono 1999), but so far it has not been used frequently for coloring textile products, whereas the color produced is very interesting to be explored and developed. Shallot which belongs to the family Liliaceae has characteristic layers in tuber form (Rahayu et al. 2004). The colors from shallot skin range from yellow to dark brown. The shallot skin has a cluster of color carriers or chromophore that is the cluster of carbonyl so it can be used as strong textile coloring agent (Marganingsih 2006). The objectives of this study were to use the shallot skin as a textile dye and to evaluate the color fastness of cotton cloth dyed with extract of shallot skin. 


\section{MATERIALS AND METHODS}

\section{Materials}

The materials used to make dyes were shallot skin and additional materials for fixation, namely alum, whiting, and tunjung. Tunjung is a textile coloring material obtained from waste that is used as a fixation medium and can produce three color gradations, from dark brown to light brown. The equipment for mordanting process were scales, aluminum pans, stirrers, stoves, buckets, ropes for drying cloth, thermometers, and litmus paper. Additional tools used for the extraction process were: alum pot, stove, stopwatch, measuring cups, stirrers, and filter.

\section{Procedures}

The stages of utilizing shallot skin waste for textile dye were the preparation stage and the color fastness processing.

\section{The preparation stage}

The preparation stage consisted of mordanting, extraction of the dye from the plants and fixation of the color. Mordanting process is the process of putting the alum, chalk, tunjung or other metal elements into the cloth fiber so that it will react with the dye (Kavak et al. 2010; Suprapto 2005). This process determines the success of dyeing using natural dyes. The mordanting purpose is to strengthen the cloth absorbance of natural dyes. Several natural dyes will fade without pretreatment (mordanting) with a certain chemical on its media. Before mordanting, the weight of dry cloth was recorded to determine the weight of dyes to be used.

The standard recipe for silk cloth mordanting is: "500 grams of cloth, 100 grams of alum, and 17 liters of water" (Susanto 1980). Formulation of alum textiles was used specifically for the media fixation. Alum, chalk, and tunjung were purchased at the batik textile store. Based on the calculation, the materials used were: 150 of cloth, 5 liters of water and 30 grams of alum.

The cloth that had been soaked overnight was put in a hot alum solution for one hour, and stirred occasionally, so all parts of the cloth were submerged. Then, the fire was turned off, and the cloth was soaked for one night. After that, it was washed, aerated until dry, then ironed. The fabric was ready to use.

\section{Extraction process}

The steps of making natural dyes from shallot skin were as follows: $500 \mathrm{~g}$ of shallot skin was boiled with $5 \mathrm{~L}$ of water for 1 hour. After that, the shallot skin pulp was separated with filtering to get solution. Fabric that had been processed with the dyeing immersion was put into the boiling solution for less than $15 \mathrm{~min}$. Then, it was drained, and it could be dyed again in any desired color. After dyeing, fixation was done.

\section{Fixation process}

The steps of making fixation solutions were: $70 \mathrm{~g} / \mathrm{L}$ of alum, $50 \mathrm{~g} / \mathrm{L}$ of chalk, $20 \mathrm{~g} / \mathrm{L}$ of tunjung, was dissolved in water (alum was heated to dissolve quickly). The dried cloth was put in fixation solution and cooled for about 5 $\min$. Then it was drained, washed with cleaned water, then dried in the shade.

\section{Color fastness processing}

Cold mordanting. One hundred grams of alum was dissolved in $2 \mathrm{~L}$ of freshwater, then heated until the boiling point. Then, it was lifted from the stove, and $3 \mathrm{~mL}$ of TRO and $8 \mathrm{~L}$ of freshwater was added. Then, $250 \mathrm{~g}$ of batik cloth was soaked for 15 minutes, and drained for immersion in the extraction solution. A thousand grams of dry shallot skin was immersed in 10 liters of freshwater, and boiled until the volume decreased to a half. Then it was dried. The dye and extraction solution were separated through filtering.

Immersion dyeing. The fabric was put into the extraction solution, stirred until all parts were evenly immersed, and then let it immersed for 15 minutes. After that, it was hanged on clotheslines in the shade until it was dry or slightly dry, and then immersion and drying were repeated until the desired color had been achieved.

Fixation. The fixation proses are intended to strengthen the bond between the fiber and the dye. The fixation was done using diazo salt, made with the following procedures. Alum: $70 \mathrm{~g}$ of alum was dissolved in $500 \mathrm{~mL}$ of hot water, and then added with $500 \mathrm{~mL}$ of cold water. Chalk: $50 \mathrm{~g}$ of chalk was dissolved in $500 \mathrm{~mL}$ of hot water and then added with $500 \mathrm{~mL}$ of cold water. Tunjung: $20 \mathrm{~g}$ of tunjung was dissolved in $500 \mathrm{~mL}$ of hot water and then added $500 \mathrm{~mL}$ of cold water. The three solutions were stored for 24 hours. Only the clear solution was taken. Solutions were used immediately. The cloth that had been dyed and dried was put in alum solution, chalk or tunjung for \pm 3 minutes. Then, it was removed, rinsed thoroughly with fresh water, drained and dried. Then, the cloth was put in 10 liters of boiled water, added with $100 \mathrm{~g}$ of starch, and stirred until all the wax disappeared. After that, the cloth was put in cold water, rinsed, drained and dried in the shade.

Washing. The washing was done after the fixation process to remove the dyes stuck on the fiber surface and to spread the color absorption (Hasanudin et al. 2001). After washing, the next step was the color fastness test.

\section{The color fastness test}

The color fastness test aims to find out the color resistance to fabric treatment and to find out the right treatment which last longer. The color fastness was conducted to know the level of color changes (no change of color, slight change, moderate change, or complete change), using the standards of color changes made by the Society of Scientists and Colorists (SDC) in the United Kingdom and the the Association of Chemists and Colorists (AATCC), in the United States. There are two types of standard, namely the Gray Scale for color changes due to color fading and the Staining Scale, for staining of white cloth with the coloring material. In the Gray scale, the color fastness was assessed by comparing the differences between the test sample and the original sample with the corresponding differences from the standard series of color changes described by the Gray Scale, and expressed 
in Adam chromatography score formula, listed in Table 1.

The accuracy of column matrix

The exact colorimetric specifications of the standard gray color and changes in the color of the Gray Scale were calculated from the formula of Adam's static score in units of C.D. Point 5 means there is no change in color, while point 1 means there are considerable color changes. In the Staining Scale, the stained white cloth was compared with the one which was not stained, and the difference between the two was scored using chromatic score as described in Table 2. The results of the color fastness evaluation of the Gray Scale or Staining Scale are described in Table 3.

\section{Data analysis}

This qualitative study used Staining Scale and Grey Scale standards to assess the results of dyeing.

\section{RESULTS AND DISCUSSION}

\section{The results of dyeing using shallot skin}

The results of dyeing using shallot skin extract are shown in Figure 1.

\section{The color fastness evaluation}

In using Gray Scale the color changes in brightness, darkness, or combination were not assessed. The basis for evaluation was the overall difference or contrast between the original test sample and the example tested already.

\section{The color fastness of cotton cloth dyed with extract of shallot skin}

The summary of the test results (Tables 4-7) are as follows. The score of color fatness in cotton cloth using natural dyes from shallot skin with alum fixation was 3-4 or (sufficient) based on color change, and 3 (sufficient) based on color staining. The score of color fastness with chalk fixation was 2 (poor) based on color change, and 3 (sufficient) based on color staining. The score of color fastness with fixation of tunjung was 3-4 (sufficient) based on color change, and 2 (deficient) based on staining scale.
Table 1. Standard evaluation table of color change in the Gray Scale

\begin{tabular}{lcc}
\hline $\begin{array}{c}\text { The value of } \\
\text { color fastness }\end{array}$ & $\begin{array}{c}\text { Color difference (in } \\
\text { C.D) }\end{array}$ & $\begin{array}{c}\text { Tolerance for work } \\
\text { standard (in C.D) }\end{array}$ \\
\hline 5 & 0 & 0.0 \\
$4-5$ & 0.8 & \pm 0.2 \\
4 & 1.5 & \pm 0.2 \\
$3-4$ & 2.1 & \pm 0.2 \\
3 & 3.0 & \pm 0.2 \\
$2-3$ & 4.2 & \pm 0.3 \\
2 & 6.0 & \pm 0.5 \\
$1-2$ & 8.5 & \pm 0.7 \\
1 & 12.0 & \pm 1.0 \\
\hline
\end{tabular}

Table 2. Scoring table of color in the staining scale

\begin{tabular}{lcc}
\hline $\begin{array}{c}\text { The value of } \\
\text { color fastness }\end{array}$ & Color difference & $\begin{array}{c}\text { Tolerance for } \\
\text { standard }\end{array}$ \\
\hline 5 & 0 & 0.0 \\
$4-5$ & 2.0 & \pm 0.3 \\
4 & 4.0 & \pm 0.3 \\
$3-4$ & 5.6 & \pm 0.4 \\
3 & 8.0 & \pm 0.5 \\
$2-3$ & 11.3 & \pm 0.7 \\
2 & 16.0 & \pm 1.0 \\
$1-2$ & 22.6 & \pm 1.5 \\
1 & 32.0 & \pm 2.0 \\
\hline
\end{tabular}

Table 3. The evaluation of the result of color density to the scores of the Gray scale or Staining Scale

\begin{tabular}{ll}
\hline The value of color fastness & The description of color fastness \\
\hline 5 & Excellent \\
$4-5$ & Good \\
4 & Good \\
$3-4$ & Fairly Good \\
3 & Fair \\
$2-3$ & Poor \\
2 & Poor \\
$1-2$ & Very Poor \\
1 & Very Poor \\
\hline
\end{tabular}

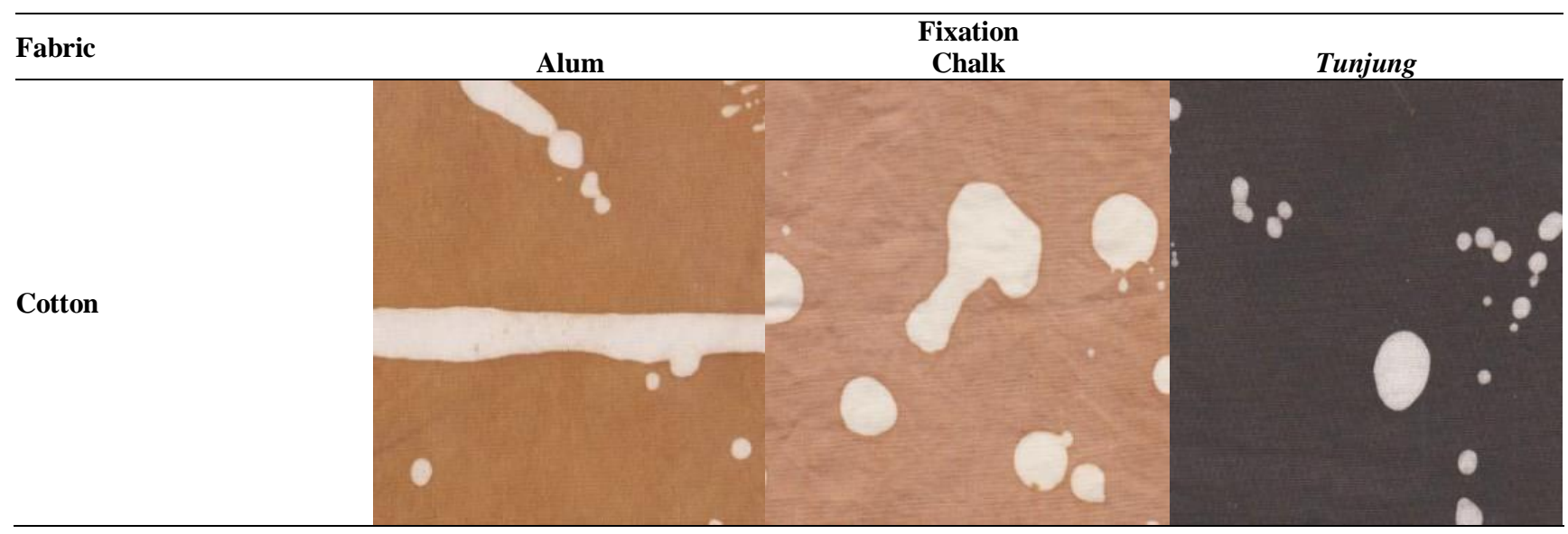

Figure 1. The test results from natural dyeing using shallot skin 
Table 4. The color change of cotton fabric using the Gray Scale

\begin{tabular}{ccccc}
\hline Test & Shallot skin & Description \\
\hline 1 & Alum & Chalk & Tunjung & Fairly Good \\
2 & $3-4$ & 2 & $3-4$ & Fairly Good \\
3 & 3 & 2 & $3-4$ & Fairly Good \\
\hline
\end{tabular}

Table 5. The staining of cotton fabric using the Staining Scale

\begin{tabular}{lcccl}
\hline Test & Alum & Chalk & $\begin{array}{c}\text { Shallot skin } \\
\text { Tunjung }\end{array}$ & Description \\
\hline 1 & 3 & 3 & $3-4$ & Fairly Good \\
2 & 3 & 3 & $3-4$ & Fairly Good \\
3 & 3 & 3 & $3-4$ & Fairly Good \\
\hline
\end{tabular}

Table 6. The changes of color using the GrayScale. CD stands for color difference

\begin{tabular}{|c|c|c|c|c|c|c|}
\hline \multirow[t]{2}{*}{ Test } & \multicolumn{5}{|c|}{ Shallot skin } & Tunjung \\
\hline & GS & CD & GS & CD & GS & CD \\
\hline 1 & $3-4$ & 1.9 & 2 & 5.5 & $3-4$ & 1.9 \\
\hline 2 & 3 & 2.8 & 2 & 5.5 & $3-4$ & 1.9 \\
\hline 3 & $3-4$ & 1.9 & 2 & 5.5 & $3-4$ & 1.9 \\
\hline Total & & 6.6 & & 16.5 & & 5.7 \\
\hline Value & $3-4 \mathrm{Fc}$ & Good & & & $3-4 \mathrm{Fc}$ & Good \\
\hline
\end{tabular}

Table 7. The staining of color using the staining scale

\begin{tabular}{|c|c|c|c|c|c|c|}
\hline \multirow{3}{*}{ Test } & \multicolumn{6}{|c|}{ Shallot skin } \\
\hline & \multicolumn{2}{|c|}{ Alum } & \multicolumn{2}{|c|}{ Chalk } & \multicolumn{2}{|c|}{ Tunjung } \\
\hline & SS & CD & SS & CD & SS & CD \\
\hline 1 & 3 & 7.5 & 3 & 7.5 & $3-4$ & 5.2 \\
\hline 2 & 3 & 7.5 & 3 & 7.5 & $3-4$ & 5.2 \\
\hline 3 & 3 & 7.5 & 3 & 7.5 & $3-4$ & 5.2 \\
\hline Total & & 22.5 & & 22.5 & & 15.6 \\
\hline Value & \multicolumn{2}{|c|}{3 Fair } & \multicolumn{2}{|c|}{3 Fair } & \multicolumn{2}{|c|}{2 Poor } \\
\hline
\end{tabular}

\section{Discussion}

Cloths are complex materials made of various woven thread (Sadeghi et al. 2013). Cloth coloring has become aesthetic work which still exists until now. The harmony between cloth types and designs improves the style of clothes (Kim et al. 2013). Cloth coloring becomes a trend which is much in demand by the people nowadays. Natural dyes from plants have been recently found as the new breakthrough in giving multifunction characteristics to the surface of textiles such as antimicrobial (Kalia et al. 2013), insect repellent, deodorant, and UV protection (Shahid-ulIslam and Mohammad 2015). Dyes can be used to give the color on various materials technically described as substrate. Dyes are applied in water solution, and need mordant to speed up the color absorption (Sivakumar et al. 2011). The character that is caused by natural dyes is to give a unique, light, static and deep impression. In addition, natural dyes are able to express various types of hues according to different mordant. Wastewater has a relatively less amount when compared to synthetic dyes (Min 1998; Nam 1998). The natural pigment properties of onion skin extract when applied to silk fabrics, can overcome the yellowing of silk fibers (Cho 1995). Cloth coloring in this research used a dye, namely shallow skin waste. In the fixation step, cloth coloring was locked using alum, chalk, and tunjung in order to produce gradation of brown color (Tera et al. 2012). Alum, chalk, and tunjung are the fixation media which can be used only for natural dyes. Using shallot waste as a dye saves money and at the same time recycle material as an effort to use natural resources efficiently, unlike the use another expensive natural dye from tengger trees which is difficult to find (Sataev et al. 2014). After fixation is conducted, color fastness test on the cloth must be done so that the result can be accepted by the market.

The results of color fastness test showed that the color fastness of cotton cloth dyed with shallot skin extract using alum fixation was fairly good based on color change and sufficient based on staining scale. The alum functions as a chemical enabling reaction between the cloth and the dye (Mozaffari and Maleki 2018). As fixator, alum tends to produce medium color, so the color of shallot skin which is usually brown becomes medium brown when it is fixed with alum.

The test results using chalk fixation showed that the color fastness was poor based on color change, but sufficient based on staining scale. The use of chalk as fixator gives good influence to lock and create light brown color. Chalk is mordant which can result in good color fastness and absorption from natural dyes like shallot skin (Wijesirigunawardana and Perera 2018). Other results with tunjung fixation showed that the color fastness was sufficient. As medium fixation, tunjung plays a good role in the absorption and locking of color, resulting in dark brown color (Ubarhande et al. 2014).

\section{REFERENCES}

Cho KR. 1995. A study of natural Dye (8)-Finish of silk by onion skin quercetin pigment. Korean Soc Dyers Finishers 7 (3): 1-10.

Hasanudin, Widjiati M, et al. 2001. Research on the Application of Natural Color Substances and their Combinations on Batik Products and Craft Textiles. Industry and Trade Research and Development Agency, Yogyakarta. [Indonesian]

Kabra AN, Khandare RV, Govindwar SP. 2013. Development of a bioreactor for remediation of textile effluent and dye mixture: A plant-bacterial synergistic strategy. Water Research 47 (3): 10351048.

Kalia S, Thakur K, Celli A, Kiechel MA, Schauer CL. 2013. Surface modification of plant fibers using environment-friendly methods for their application in polymer composites, textile industry and antimicrobial activities: A review. J Environ Chem Eng 1 (3): 97 112.

Kavak F, Onal A, Seyfikli. 2010. Usage of willow extract as mordant agent and dyeing of wooden and fiber samples with onion (Allium cepa) shell. Rasayan J Chem 3 (1): 1-8.

Kim D, Koh W, Narain R, Fatahalian K, Treuille A, O’Brien JF. 2013. Near-exhaustive precomputation of secondary cloth effects. ACM Trans Graphics 32 (4): 1-7. 
Lestari K, Prawirohartono S. 1999. Revival of Natural Colours. Dekranas, Yogyakarta. [Indonesian]

Madsen B, Gamstedt EK. 2013. Wood versus plant fibers: similarities and differences in composite applications. Adv Mater Sci Eng 2013: 1-14.

Marganingsih M. 2006. Onion Skin as an Alternative Coloring The Batik Process. Department of Arts / Textile Craft, Faculty of Letter and Arts, Sebelas Maret University. Surakarta. [Indonesian]

Min GZ. 1998. The Korean Textile; the initial number. The Korean Fiber Society: Tradition Textile Subcommittee, Seoul.

Mozaffari E, Maleki B. 2018. Alum mineral and the importance for textile dyeing. Fashion Technol Textile Eng 3 (4): 1-3.

Nam SW. 1998. Dyeing by natural dye; fiber technology and industry. Korean Fiber Soc 2 (2): 238

Sadeghi I, Bisker O, de Deken J, Jensen H. W. 2013. A practical microcylinder appearance model for cloth rendering. ACM Trans Graphics 32 (2): 1-12.

Sataev M. S, Koshkarbaeva S. T, Tleuova A. B, Perni S, Aidarova S. B, Prokopovich P. 2014. Novel process for coating textile materials with silver to prepare antimicrobial fabrics. Colloids and Surfaces A: Physicochemical and Engineering Aspects 442: 146-151.
Shahid-ul-Islam, Mohammad F. 2015. Natural colorants in the presence of anchors so-called mordants as promising coloring and antimicrobial agents for textile materials. ACS Sustain Chem Eng 3 (10): 23612375.

Sivakumar V, Vijaeeswarri J, Anna JL. 2011. Effective natural dye extraction from different plant materials using ultrasound. Industr Crops Prod 33 (1): 116-122.

Suprapto H. 2005. Mordanting Knowledge. Natural Batik "BIXA", Yogyakarta. [Indonesian]

Susanto S. 1980. The Art of Indonesian Batik Craft. Department of Industry Republic of Indonesia, Jakarta. [Indonesian]

Tera FM, Elnagar KE, Mohamed SM. 2012. Dyeability and light-fastness properties of onion scale dye on different fabric types for conservation applications. J Textile Apparel Technol Manag 7 (3): 16.

Ubarhande DP, Landage S, Kulkarni SG. 2014. To impart lotus effect on cotton fabric using combination of silica nanoparticles \& water repellent agent. Intl J Eng Res Technol 3 (5): 2461-2466.

Wijesirigunawardana PB, Perera BG. 2018. Development of a cotton smart textile with medicinal properties using lime oil microcapsules. Acta Chim Slov 65: 150-159. 